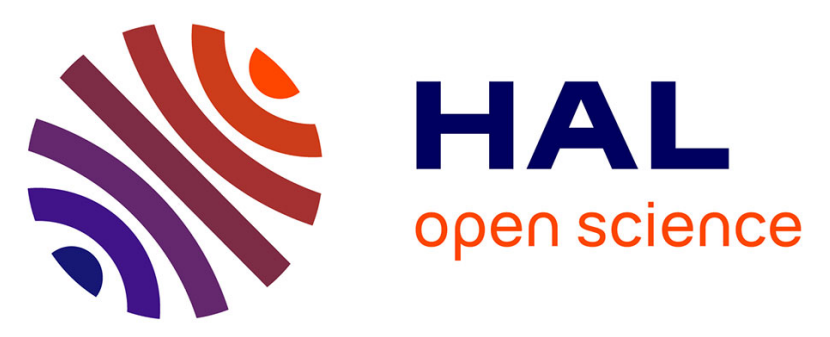

\title{
Evaluating critical metals contained in spintronic memory with a particular focus on Pt substitution for improved sustainability
}

\author{
A. Palomino, J. Marty, S. Auffret, I. Joumard, Ricardo C. Sousa, I.L. \\ Prejbeanu, B. Ageron, B. Dieny
}

\section{To cite this version:}

A. Palomino, J. Marty, S. Auffret, I. Joumard, Ricardo C. Sousa, et al.. Evaluating critical metals contained in spintronic memory with a particular focus on Pt substitution for improved sustainability. Sustainable Materials and Technologies, 2021, pp.e00270. 10.1016/j.susmat.2021.e00270 . hal-03170821

\section{HAL Id: hal-03170821 \\ https://hal.science/hal-03170821}

Submitted on 16 Mar 2021

HAL is a multi-disciplinary open access archive for the deposit and dissemination of scientific research documents, whether they are published or not. The documents may come from teaching and research institutions in France or abroad, or from public or private research centers.
L'archive ouverte pluridisciplinaire HAL, est destinée au dépôt et à la diffusion de documents scientifiques de niveau recherche, publiés ou non, émanant des établissements d'enseignement et de recherche français ou étrangers, des laboratoires publics ou privés. 


\title{
Evaluating critical metals contained in spintronic memory with a particular focus on Pt substitution for improved sustainability.
}

\author{
A. Palomino ${ }^{1 *}$, J. Marty ${ }^{2}$, S. Auffret ${ }^{1}$, I. Joumard ${ }^{1}$, R.C. Sousa ${ }^{1}$, I. L. Prejbeanu ${ }^{1}$, B. \\ Ageron $^{2}$ and B. Dieny ${ }^{1}$ \\ ${ }^{1}$ Univ. Grenoble Alpes, CEA, CNRS, Grenoble INP, IRIG-SPINTEC, 38000 Grenoble, France \\ ${ }^{2}$ Laboratoire CERAG, Université Grenoble Alpes, 38400 Saint Martin d'Hères, France \\ E-mail: alvaro.palominolopez@cea.fr
}

\begin{abstract}
Thanks to their unique combination of properties: non-volatility, speed, density and write endurance, spintronic memory called spin transfer-torque Magnetic Random Access Memory (STT-MRAM) is expected to play a major role in the future development of the Internet of Things (IoT) and more generally in information and communication technologies. This type of spintronic device is usually made of materials, some of which can be classified as critical. Recent studies have evaluated critical materials contained in magnetic random access memory [1,2]. However, in those cases the type of memory analyzed belongs to the first generation of MRAMs developed in the early 2000s. Nowadays, the memory devices are magnetized perpendicularly to the plane of the layers and contain a synthetic antiferromagnet (SAF) that provides a high coercivity to the STT-MRAM reference layer with reduced stray field. This SAF is typically made of cobalt (Co) and platinum (Pt) multilayers antiferromagnetically coupled across a thin ruthenium $(\mathrm{Ru})$ layer. Due to the high-embodied energy of platinum group metals (PGMs), a common concern when evaluating these materials is the environmental risk associated with their production. An evaluation of the environmental and economic risks of using such multilayers is first reported here, followed by a discussion of its supply risk. Substitution of $\mathrm{Co} / \mathrm{Pt}$ multilayers by $\mathrm{Co} / \mathrm{Ni}$ multilayers can lead to a reduction by 3-4 orders of magnitude in terms of energy requirements or global warming potential (GWP) associated with the use of these multilayers. An alternative concept based on perpendicular shape anisotropy (PSA) can also yield a reduction by 1-2 orders of magnitude in these quantities. However, for the case of STT-MRAM, tiny quantities of PGM layers are used in comparison with the mass of the silicon wafer on which these type of devices are grown. Therefore, the environmental and economic impact of the silicon wafer fabrication is found to be much higher than that of the PGM materials incorporated in the STT-MRAM stacks. Nonetheless, the high supply risk associated with PGMs remains a reason for awareness. One explored possibility is a SAF structure based on $\mathrm{Co} / \mathrm{Ni}$ multilayers which can have similar performance. A second more challenging alternative is also proposed based on the aforementioned PSA concept. Finally, we address the case of several other metals identified by the European Commission as critical and used in MRAM such as W or Ta, both recently included in the EU's Conflict Minerals Regulation released in January 2021 [3].
\end{abstract}

Keywords: Magnetic tunnel junction, MRAM, Critical materials, Sustainable electronics

\section{Introduction}

In the last few decades, concerns about climate change have risen and solutions for the demanding future energetic scenarios are investigated, some of them being controversial in terms of material requirements.
Following the emergence of the IoT (Internet of Things), the amount of energy required for information and communication technology (ICT) is expected to drastically increase in the coming years, as seen in Figure 1.

According to Seagate [4], the world will produce 175 zettabytes of data in 2025. Belkhir [5] reports that the global greenhouse gas emissions (GHGE) from ICT could increase 
from $1.6 \%$ of the total in 2007 up to $14 \%$ in 2040 , using the 2016 level of global production as reference.

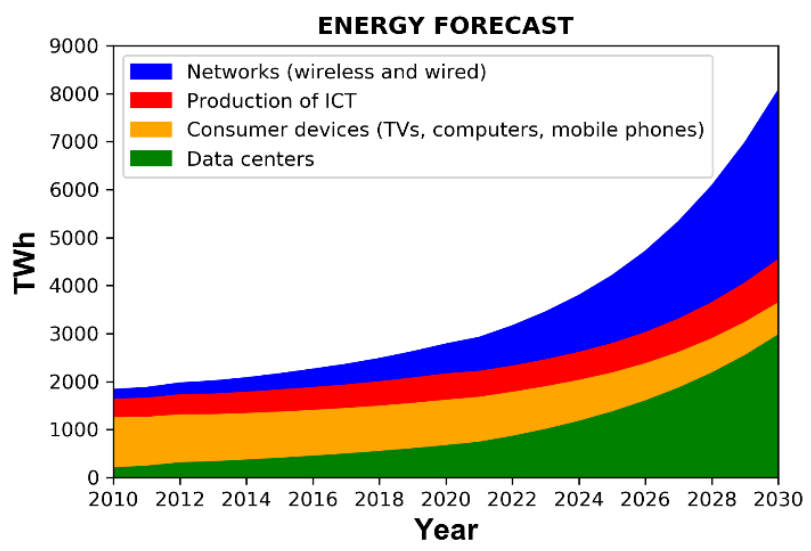

Figure 1. Energetic forecast of information and communication technologies (ICT) for 2030 (Data from [6]).

To cope with this massive amount of data, artificial intelligence (AI) for managing data and new architectures for computing are being investigated [7].

Furthermore, due to the expected increase of 'real-time' generated data, the use of non-volatile memory (NVM) might be a key factor for reducing the energy consumption while processing increasing amounts of data. A particularly promising NVM candidate is the Magnetic Random Access Memory (MRAM) [8,9].

Alongside the need to reduce the energy impact of the ICT sector, another concern is the extensive use of critical metals that possess certain unique properties [10]. In $2018 \mathrm{Ku}$ et al. [1] evaluated the potential supply chain constraints for the expected needs of emerging data storage technologies. The conclusion of this study was that the use of platinum group metals (PGMs) for gate layers in some Ferroelectric RAM (FeRAM) and MRAM device structures can be problematic in terms of supply due to the small annual production of Pt and Ir, and that alternative solutions must be found. In September 2020, the European Commission included in its report on raw materials for strategic technologies and sectors [2] the results of $\mathrm{Ku}$ et al. for the evaluation of material constraints. In this earlier study, the type of MRAM analyzed corresponds to first generation, using in-plane anisotropy developed in the early 2000s. Nowadays, MRAM in production uses spin transfer torque writing, in out-of-plane magnetized magnetic tunnel junctions (MTJ) [8,9]. These junctions comprise a synthetic antiferromagnetic structure (SAF) including PGM materials. The SAF is intended to provide thermal stability to the reference layer magnetization and to reduce the stray field exerted by the reference layer on the storage layer magnetization. It is commonly made of three materials: cobalt $(\mathrm{Co})$, platinum $(\mathrm{Pt})$ and ruthenium $(\mathrm{Ru})$, or the alternatives palladium $(\mathrm{Pd})$ and iridium (Ir). Figure 2a shows the composition of a typical p-STT-MRAM where multilayers comprising (Pt 0.25/Co 0.5nm) repeats provide a strong perpendicular magnetic anisotropy (PMA) while a Ru layer $0.9 \mathrm{~nm}$ thick is used to obtain antiferromagnetic coupling between the top and bottom SAF components.

Figure 2b shows the two stable magnetic configurations: with parallel or antiparallel alignment, corresponding to resistance states ( $R_{P}$ with low resistance and high resistance $R_{A P}$ ) defining the binary states of the memory. Setting either state can be achieved through an external applied magnetic field or spin polarized current.

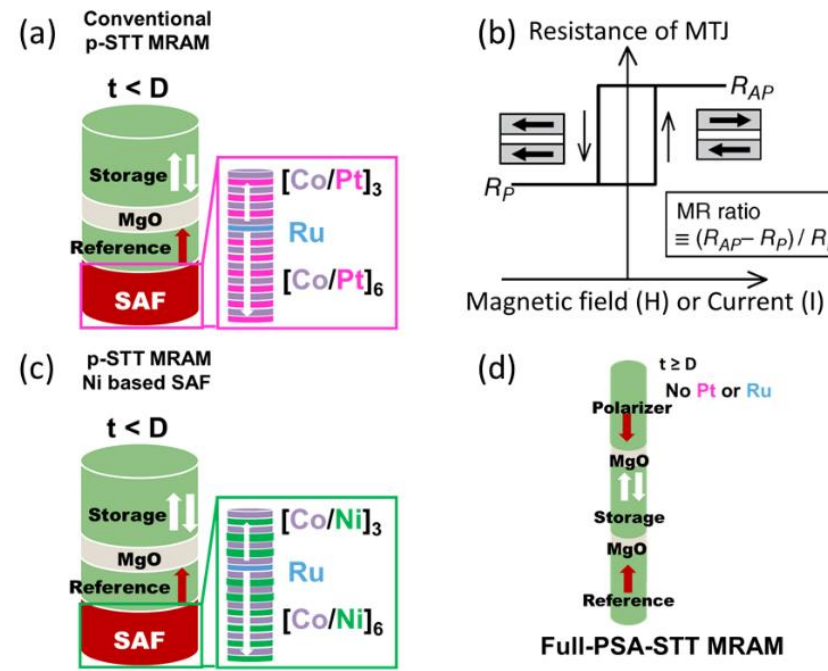

Figure 2. (a) Schematic of a typical p-STT-MRAM. The SAF is composed of $\mathrm{Co} / \mathrm{Pt}$ layers in antiparallel alignment through RKKY coupling induced by the Ru layer. The aim of this antiferromagnetic coupling is a reduction of the stray field that the reference layer creates on the storage layer; (b) Hysteresis loop of a typical device, the two stable resistance states at zero field are used to store information (from [9]); (c) $\mathrm{Co} / \mathrm{Ni}$ based alternative solution with $\mathrm{Ni}$ replacing Pt; (d) Full-PSA-STT-MRAM alternative without Pt or Ru. The reference layer stray field is here compensated by a top layer, with magnetization set antiparallel to the reference layer.

In perpendicular STT-MRAM, the magnetization of the storage magnetic layer is usually made of ferromagnetic materials such as $\mathrm{Co}, \mathrm{Fe}, \mathrm{Ni}$ or their alloys with additional boron to create an amorphous layer upon deposition. Reversing the storage layer direction sets the logic state ' 0 ' or ' 1 ' for parallel or antiparallel alignment with the reference layer magnetization. Thus, bit information is coded in the relative orientation between reference and storage layer magnetizations. Information is read from the MTJ resistance state, defined by the tunnel junction TMR signal, as shown in Figure $2 b$. The TMR amplitude is defined as the relative resistance change between the two stable magnetic configurations and is typically in the range 100\%-300\% in MgO based MTJs.

During operation, it is crucial that the reference layer direction is stable, with a coercivity much larger than any applied magnetic fields that the device may be exposed to in operation, and higher than the storage layer coercivity. The coercivity 
results from the perpendicular magnetic anisotropy provided by the $(\mathrm{Co} / \mathrm{Pt})$ multilayers. Both $\mathrm{Pt}$ and $\mathrm{Ru}$ present in conventional p-STT-MRAM belong to a group of elements known as PGM («Platinum Group Metals ») whose mineral reserves are highly concentrated in a few locations, and their mining and posterior processing has very significant environmental impact, because of the low initial ore concentration of only a few ppm.

Figure $2 \mathrm{c}$ and $\mathrm{d}$ show two possible alternatives to the conventional STT-MRAM structure: a SAF where Nickel (Ni) plays the role of $\mathrm{Pt}$ (Figure 2c) and a perpendicular shape anisotropy (PSA) based alternative (Figure 2d), free of Pt and $\mathrm{Ru}$. In the case of the PSA alternative, the material used for the reference and top polarizer can be made of ferromagnetic elements $(\mathrm{Fe}, \mathrm{Co}, \mathrm{Ni})$ or their alloys, properly engineered by varying its geometrical aspect ratio to achieve high thermal magnetic stability. This second alternative is a novel approach, but requires a strict dimensional control of the pillar diameter in the $10-20 \mathrm{~nm}$ range, since the layer properties are defined by the pillar aspect ratio.

In this report, different factors used by the EU methodology for assessing criticality are first detailed for the case of Pt [11]. Based on these elements, the impact of Pt use in perpendicular STT-MRAM is then specifically addressed. This leads us to conclude that due to the small amount of Pt required for device fabrication, its substitution by a more common and environmentally friendly material would have a not so significant economic or environmental impact. Actually, it is shown that improvements to $\mathrm{Si}$ wafer fabrication process would generate the most beneficial environmental impact, not only for STT-MRAM but more generally for most microelectronic components. However, if access to $\mathrm{Pt}$ is completely suppressed as the result of supply chain disruptions in the highly concentrated PGM production, substitution must be investigated as a risk mitigation measure.

\subsection{Criticality assessment of Pt in p-STT-MRAM}

As mentioned by Frenzel et al. [12], the criticality of a material is not an intrinsic property but depends on the consumer and the considered time-period. In evaluating material criticality, it is usual to focus on supply risk, environmental implications and economic importance [13]. These factors lead to material criticality assessments as the one in Figure 3, showing some critical materials and also including typical materials used in MRAM technology.

It is readily observed that PGMs (Platinum, Ruthenium and Palladium) lie high in the critical region of supply risk and economic importance.

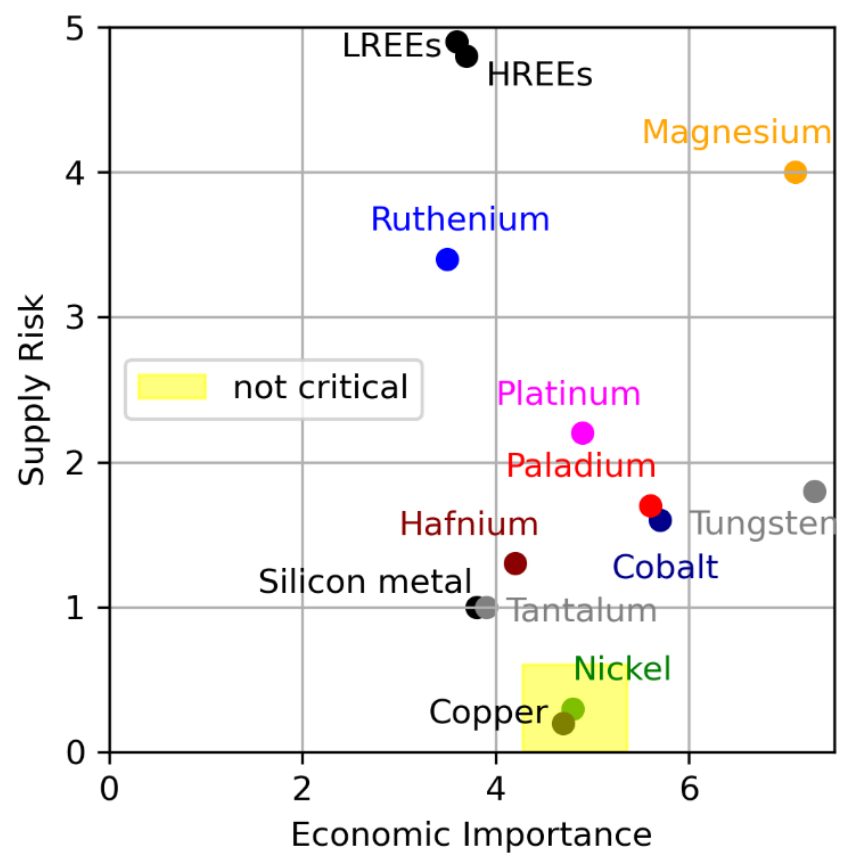

Figure 3. Criticality assessment at EU level in 2017 (selected materials). Materials highlighted in yellow are classified as non-critical in 2017. Source: data from European Commission [14, 15]. HREEs and LREEs stand for heavy/light rare earth elements respectively.

\section{Economic importance}

In the EU assessment [11], economic importance is defined as the importance of a material for the EU economy in terms of end-use applications and the added value (VA) of the corresponding manufacturing sectors according to the NACE rev.2, 2-digit level statistical classification of economic activities in the European Community. The economic importance is described as follows:

Economic importance $=\sum_{s}\left(\mathbf{A}_{\mathbf{s}} \cdot \mathbf{Q}_{\mathbf{s}}\right) \mathbf{S I}_{\mathrm{EI}}$

where $Q_{s}$ defines the total added value of sector $s$ and $A_{s}$ the share of raw material of that sector. A substitution index $\mathrm{SI}_{\mathrm{EI}}$ is defined that indicates the feasibility of an alternative material. Although economic importance is not the focus of this study, it can be observed from eq.(1) that the presence of possible substitution strategies can lower the economic criticality assigned to a certain material.

\section{Supply Risk}

On the y-axis in Fig.3, supply risk (SR) reflects the risk of supply disruptions, as calculated based on the concentration of primary supply of raw material producing countries, considering their governance and trade policies. For its calculation (Eq. 2), several factors are taken into account:

$S R=\left(1-E o L_{R I R}\right) \cdot S I_{S R} \cdot$ weighted $H H I$ 
Where:

- SR=supply risk

- HHI=Herfindahl-Hirschman Index

- EoL $L_{R I R}=$ end of life recycling input rate

- SI $\mathrm{SR}=$ substitution index related to supply risk

In Equation 2, three main terms define the supply risk of a material: recyclability $\left(E o L_{R I R}\right)$, substitution index (SISR) and an indicator HHI related to the abundance of supplier countries. A complete discussion is made in the reference work of Blengini et al., 2017 [11], and these three factors are discussed next.

\section{Recyclability}

High recyclability translates into lower supply risk since it can provide a secondary flow of raw material. In the case of $\mathrm{Pt}$, very diverse recycling rates can be achieved depending on the application. Industrial applications have a recycling rate as high as $80-90 \%$ while for automotive applications, a rate of $50-60 \%$ is common [16]. In the case of electronic components, a low 5-10\% recycling rate is reported. Interestingly, a big difference in terms of recycling rates of $\mathrm{Pt}$ exists between Asia and Europe/North America as shown in Figure 4. Asia is a leader of jewellery recycling with a total of 14.45 tons from this sector (Fig.4b), while Europe/North America are leaders in auto catalyst PGM recycling (Fig.4a) with 40.25 tons recovered by recycling in 2019 .

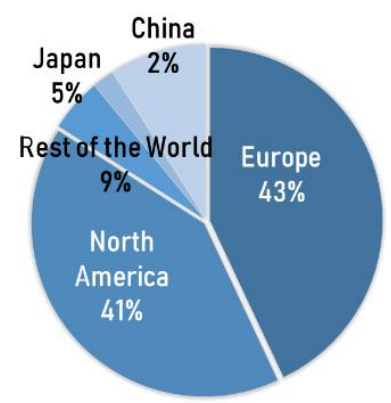

(a)

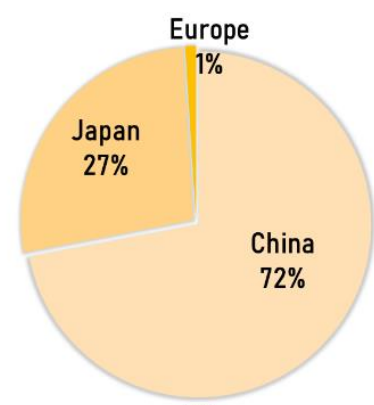

(b)
Figure 4. Autocatalyst recycling $(2018,1.42 \mathrm{moz})$ by region - Europe and North America dominant (a) Jewelry recycling (2018,510 koz) by region almost all from China and Japan (b) from [17].

The high recycling rate in Asia reflects the importance of the Chinese platinum jewellery sector (Fig.4b).

The small material volumes used in each individual microelectronic chip, as is the case of MRAM where nanometer thin layers of a large variety of metals are combined, make recycling a much more challenging process. However, Hagelüken [16,18] claims that when gold and precious metals contained in electronic scrap enter state-ofthe-art metallurgical plants, a very efficient recovery can be achieved. The difficulty relies in that many of this waste electronic and electrical equipments (WEEE) end up exported to developing and transition countries where the recycling effort is focused on only few valuable metals ('cherrypicking'). However, even for those valuable metals, the recovery rate is not very high. In conclusion, the low recycling rate in electronic applications is not due to technical reasons but rather to the difficulty in collecting billions of small objects each containing a tiny amount of scarce material, and to the difficulty of monitoring the end of life of that electronic scrap. Otherwise, significantly higher recycling rates could be achieved, in principle as high as for other sectors $[16,18]$.

Other sources of recycling can be envisioned such as the platinum which is lost during the deposition process in the chamber of the deposition tool. This is an interesting point that will be addressed further when calculating the amount of material required for the device fabrication.

In any case, attention to PGM recycling has risen in the last decades, as indicated by the rapidly increasing number of patents addressing this issue over the past 40 years. It tripled from the period $1970-1979$ to $2000-2009$ [16]. Within the worldwide supply of Platinum, the proportion recovered from recycling has increased from $10 \%$ in 2003 to $25 \%$ in 2019. $[19,20]$

\section{Substitutability}

The second term when assessing supply risk in Eq. (2) corresponds to a substitution index (SI). Supply risk can be reduced when a substitution material exists which is produced in large quantity, has a low criticality and is mined as a primary product rather than a co/by-product. Global production of platinum was estimated to be 187 tons compared to the 1750 kilotons of nickel average in the $2010-2014$ period $[14,15]$.

In terms of criticality, as seen in Figure 3, the EU classifies nickel as non-critical in 2017 (yellow area). Finally, both Pt and $\mathrm{Ni}$ are obtained as primary products during mining as shown in Figure 5. 


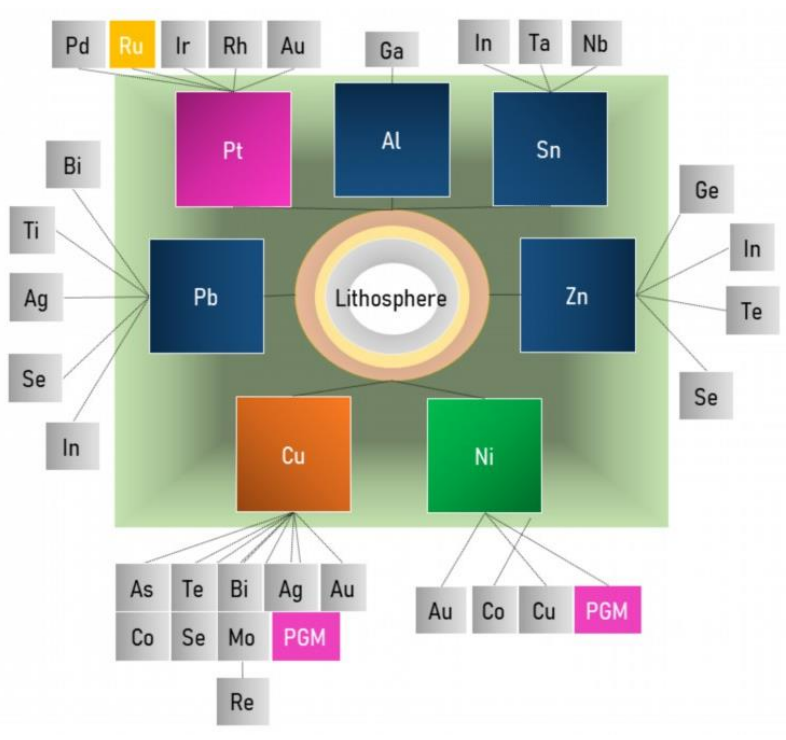

Figure 5. Metal primary products (into the green-light area) and their respective by-products. Re-draw from UK Energy Research Center [21].

Another important factor in material substitution deals with the share of material used in the application of interest. In the case of p-STT-MRAM, the amount of material required is a key point when evaluating the importance of substitution. Replacement of Pt is usually performed using other PGM such as Pd. However, its world production remains small (209 tons). $\mathrm{Pd}$ is also classified as critical and besides, is effectively a by-product of $\mathrm{Pt}, \mathrm{Ni}$ and $\mathrm{Cu}$ mining. Therefore, substituting Pt by Pd would not be an ideal option.

In the car industry, both $\mathrm{Pd}$ and $\mathrm{Pt}$ are used for the catalytic converters that reduce pollution emissions, with $\mathrm{Pt}$ more suitable for diesel and Pd for gasoline combustion engines. The price of Pd has been historically lower than that of Pt as seen in Figure 6, which represented the main driver for its substitution.

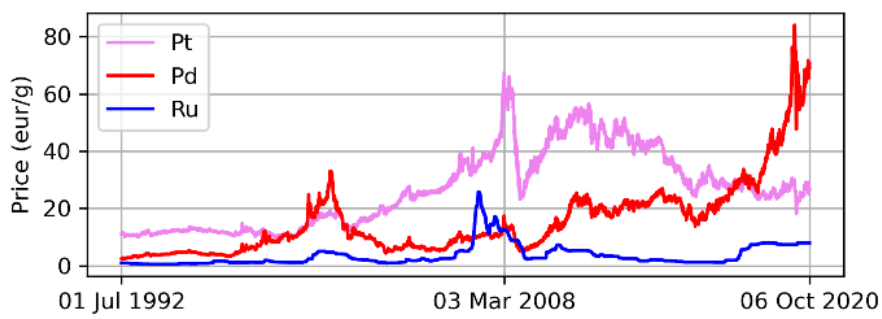

Figure 6. Price evolution ( $€ / g$ ) between Jan 2000 and May 2020 for Platinum, Palladium and Ruthenium. Source: Johnson Matthey [22].

However, in the last years this trend has reversed. These fluctuations between $\mathrm{Pt}$ and $\mathrm{Pd}$ prices over the last years can be explained by the increase of gasoline cars reported by the European Automobile Manufacturers Association (ACEA) accounting now for $59.5 \%$ of the EU market against $29.1 \%$ diesel share in the third quarter of 2019. A $6.1 \%$ increase of the gasoline share was reported and a reduction of $14.1 \%$ for diesel. This market trend comes from pressure to reduce fine particle emissions leading to lower diesel market share. In the price evolution of figure 6, the drop on PGM prices in 2008 followed the price fall of most commodities following the financial crisis of 2007-2009. A price drop also occurred in the first months of 2020 due to the impact of reduced economic activity following the breakout of the COVID-19 pandemic.

In the case of MRAM development, given the factors stated above, it is preferable to use Ni rather than substitution by $\mathrm{Pd}$ as long as the required magnetic specifications can be achieved.

\section{Herfindahl-Hirschman Index}

As previously stated, $\mathrm{HHI}$ in equation 2 , is an indicator of the concentration of supplier countries. Fig.7 compares the worldwide producers of $\mathrm{Pt}$ and Ni. Ni production (Figure 7b) is more diversified than that of $\mathrm{Pt}$ (Figure 7a).

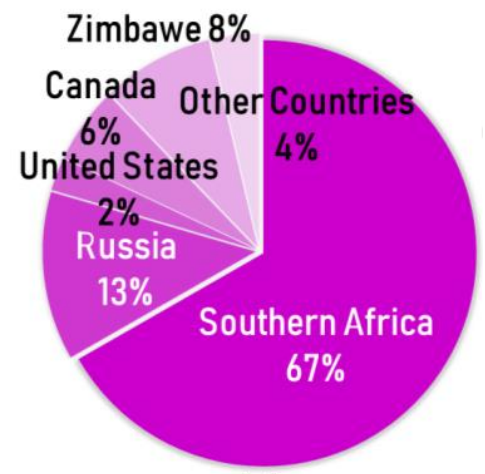

(a)

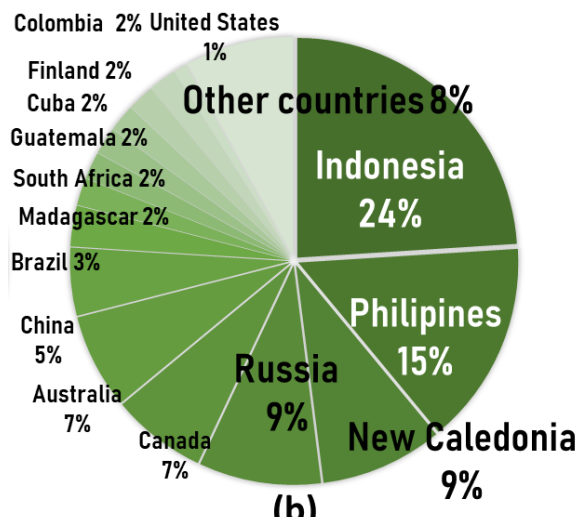

(b)

Figure 7. Pt (a) and $\mathrm{Ni}$ (b) world production of 2018 by country. U.S. Geological Survey, 2019 [23].

South Africa is the main worldwide Pt producer with $66.8 \%$ share, followed by Russia with $12.8 \%$, a country that is known to apply dual pricing for strategic resources as is the case already for natural gas exports [24]. 
The $80 \%$ of the PGM market production is concentrated in four mining companies, integrating the whole process from mining to refining: Anglo Platinum, Impala Platinum, and Lonmin Platinum from South Africa and Norilsk in Russia [25].

One of the proposed substitution alternatives to Pt consists in using $(\mathrm{Co} / \mathrm{Ni})$ multilayers to replace $(\mathrm{Co} / \mathrm{Pt})$ multilayers in STT-MRAM. However, the growth of $(\mathrm{Co} / \mathrm{Ni})$ multilayers often relies on the use of hafnium (Hf) as seed layer [26-28]. Unfortunately, $\mathrm{Hf}$ is also classified as a material with relatively high supply risk for the EU even though its production is highly concentrated in France and the US (43\% in $2010-2014,41 \%$ in US) (Figure 8a). The large Hf production in those two countries stems from their use in nuclear industry. As an alternative solution for the growth of $(\mathrm{Co} / \mathrm{Ni})$ multilayers, $\mathrm{Cu}$ seed layers have also been demonstrated to provide perpendicular magnetic anisotropy in $(\mathrm{Co} / \mathrm{Ni})$ with the advantage that $\mathrm{Cu}$ is classified as a noncritical material. The $\mathrm{Cu}$ layer provides the required (111) texture necessary to get large PMA in $\mathrm{Co} / \mathrm{Ni}$ multilayers.

The relatively high supply risk of $\mathrm{Hf}$ is explained by the fact that EU relies on a single EU company for its supply [2] while in the case of copper, Chile (26\%) and Peru (23\%) are the two main suppliers with the remaining volume being sourced from at least 12 other countries in the 2010-2014 period. As seen in Figure 8(b), the use of a $\mathrm{Cu}$ based seed layer is indeed more interesting under these circumstances.

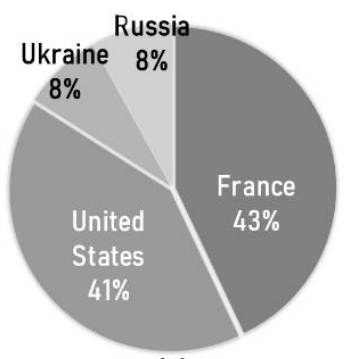

(a)

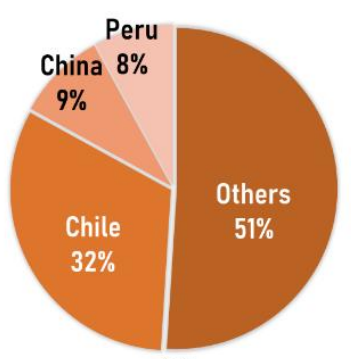

(b)
Figure 8. Hf (a) vs $\mathrm{Cu}$ (b) world production of 2010-2014. European Commission, $2017[15,16]$.

\section{Import reliance}

Import reliance is an important factor taken into account when calculating the HHI index. In the case of the EU, the reported import reliance is as high as $98 \%$ for Pt. Only about one ton is produced in Europe, Finland being responsible for $90 \%$ of this one ton supply while the remaining $10 \%$ originates from Poland. In the case of Nickel, the EU import reliance drops to 59\%. According to the European Commission study (2017), this number is sufficiently low to ensure that demand can be covered even in case of supply disruptions [15]. For the US, the reported import reliance of $\mathrm{Pt}$ is $73 \%$, with major supply sources being South Africa 44\%, Germany 15\%, United Kingdom $10 \%$ and Italy $7 \%$, while for Nickel the import reliance is $52 \%$. For Nickel, the major supply sources are Canada, Norway, Australia and Russia (U.S. Geological Survey, 2019 [23]).

\section{Discussion}

\subsection{Environmental implications}

In some studies, the introduction of Environmental Performance index aims at classifying the environmental risk as a function of the producer country [29]. It evaluates factors such as polluting emissions and waste water treatment among others. This is a crucial point when considering PGMs, since the mining and further processing require very large amounts of energy and water, as well as generating vast amounts of $\mathrm{CO}_{2}$ emissions. The low concentration of PGMs in the ore from which they are mined (few g/Ton) makes this group of metals one with the highest embodied energy [25].

In addition, the PGMs are usually found together with gold and have very similar chemical properties, such that their separation turns out to be difficult. Figure 9 displays the high energetic and water requirements of platinum group metals compared to other critical metals together with nickel, in logarithmic scale.
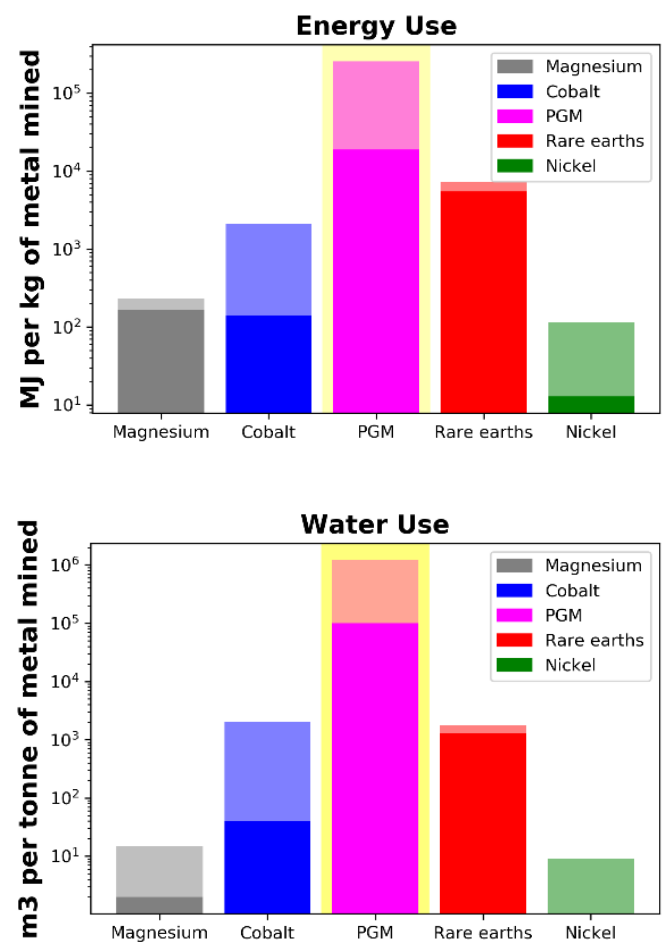

Figure 9. Energy and water requirements for the production of metals from the ore (high grade-pale colour, low grade-dark colour) in logarithmic scale. From European Commission, Report on Critical Raw Materials in the Circular Economy (2018). Energy data for nickel from [30] and water from [31]. 
It can be observed that PGMs energetic requirements are 2 orders of magnitude higher than those of cobalt or rare earths and even 3 orders of magnitude for water needs. Obviously, this serious environmental impact makes the substitution of these metals often desirable in addition to their very high price.

Nevertheless, the high environmental impact needs to be evaluated as a function of the specific technological requirements. For instance, in spintronic applications and microelectronics in general, only very small amounts of these materials are used. Nevertheless, the complete suppression of these materials can yield significant performance impacts, so that careful alternative strategies must be investigated.

Before evaluating the environmental impact and price of using Pt in perpendicular STT-MRAM, an important factor to be considered is the material wasted during the deposition process.

\subsection{Losses occurring during physical vapor deposition (PVD) of the material}

Microelectronics has been cited as an example of radical « dematerialization » as the products usually provide high value and utility while having a negligible weight. However, an interesting example is an article published by Williams et al. in 2002 where they analyze the energetic and material requirements of semiconductor devices, appropriately entitled, "The 1.7 Kilogram Microchip: Energy and Material Use in the Production of Semiconductor Devices" [32]. In this study, considering the amount of materials required during the whole fabrication process, they end up concluding that classifying microelectronic devices as examples of dematerialization may not always be correct.

In some cases $[1,2]$, the calculation of material requirements for a specific technology is done using the size of the final patterned device. However, this approach does not account for the total amount of material used in the device fabrication since to fabricate those structures, thin films need to be deposited, then etched to nanopattern the device. As a result, the real amount of material used is much higher than that contained in the final devices.

Microelectronic circuits are nowadays made of integrated components, e.g. transistors, memory dots, vias, interconnects, with characteristic dimensions in the nanometer range. This is the case in particular for MRAM technology where each memory cell is a patterned element of diameter ranging from 20 to $50 \mathrm{~nm}$. In order to fabricate these devices, several layers, each one 2-3 atoms thick, are deposited on 300 $\mathrm{mm}$ diameter wafers. Then all elementary components are nanopatterned through a sequence of lithography, etch and deposition operations. Already at the first deposition step, a significant proportion of the sputtered material is wasted in the deposition chamber.

Figure 10 schematizes a magnetron sputtering deposition process.

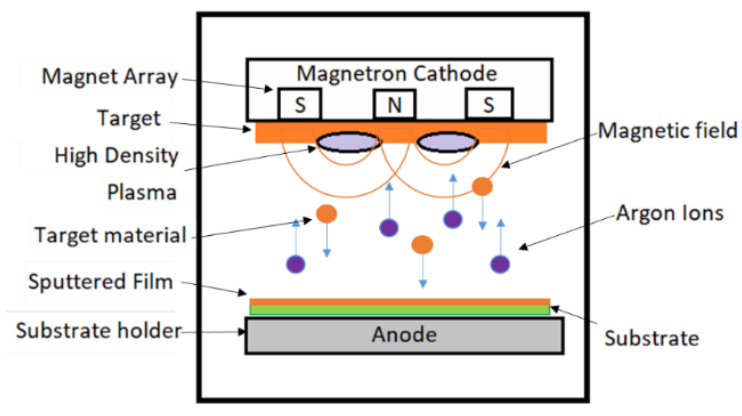

Figure 10. Schematics of magnetron sputtering process

A gaseous argon (Ar) plasma is formed in the vacuum chamber containing the material target to be deposited, as well as the substrate where the material is deposited in thin film form. The high-energy argon ions within the plasma erode the target surface, ripping atoms from the target surface. These sputtered atoms travel through the chamber and a fraction of them get deposited onto the wafer, creating a thin film. The fraction of sputtered material not reaching the substrate is actually wasted, ending up on the inner walls of the sputtering chamber, representing a net material loss during deposition. In order to meet industrial requirements, the thickness of the deposited film needs to be homogeneous to sub $\mathrm{nm}$ precision over the whole wafer. The thickness homogeneity is achieved by different strategies such as rotation or linear motion of the substrate, increasing the target to wafer distance or use of low deposition rates.

The efficiency of material utilization during deposition processes very much depends on the geometry of the tool and the conditions required for optimal uniformity of the deposited layer. It also depends on the material to be sputtered and the gas pressure during deposition.

In a patent application, Walter $\mathrm{H}$. et al described a cathode assembly conceived to reduce sputtering losses during deposition [33]. In this particular assembly, the elongated target segments are tilted toward each other with both targets made of the same material to be sputtered, reducing sputtering losses. During the film deposition, the substrate is linearly translated to ensure good film homogeneity. Besides, the length and width of the cathode exposed to the magnetic field are longer than the corresponding lengths on the substrate. For this reason, a certain amount of material ends up aside of the substrate during the deposition which contributes to the socalled target end loss. A second source of material losses is 
related with the scanning motion of the substrate and referred to as overscan loss. In this patent, it is claimed that overscan losses for a planar target can be of $33 \%$ and by using the tilted faced target, they can be reduced to $20 \%$. However, this type of geometry requires two targets for each material.

For other particular cases, deposition of only $15 \%$ of the target sputtered material onto the substrate has been reported for the case of indium tin oxide (ITO) [34].

Rossnagel reported the fraction of sputtered atoms deposited on the substrate to range from $22 \%$ to $80 \%$ depending on the sputtered material, argon pressure and throw distance of a sputtering process at $1000 \mathrm{~W}$ in $200 \mathrm{~mm}$ diameter planar magnetron [35].

When evaluating the material requirements in the next section, different material efficiency of utilization scenarios were considered (Figure 12).

Another aspect to take into account is that the material target erosion does not occur over the complete target during the sputtering process. PGMs targets are commonly recycled by refilling the eroded region. The main motivation for this recycling is the elevated cost of these materials, as the target total weight can be of few kilograms depending on the size of the wafer on which the metal is deposited. However, this target recycling is not usually done for other less expensive/more common metals. In this sense, 'end of life target' recycling is ensured for PGMs targets.

\subsection{Environmental and economic impact of $\mathrm{Pt}$ substitution in the SAF of p-STT MRAM}

In this section, the impact of Pt substitution in p-STT-MRAM by the two alternatives shown in Figure 2 is evaluated. The energy, global warming potential (GWP) and price estimated for the associated material production assuming a $72 \%$ percentage of losses during deposition are compared in Figure 11 , for a $300 \mathrm{~mm}$ wafer.

The estimated percentage of losses determines the final conclusions drawn, such that a more accurate estimation is necessary for each particular scenario, especially if smaller losses can be achieved. The reported numbers in Fig. 11 are given for the extraction of Pt present in conventional SAF and for $\mathrm{Ni}$ and $\mathrm{Co}$ in the proposed solutions as indicated in Fig.2.

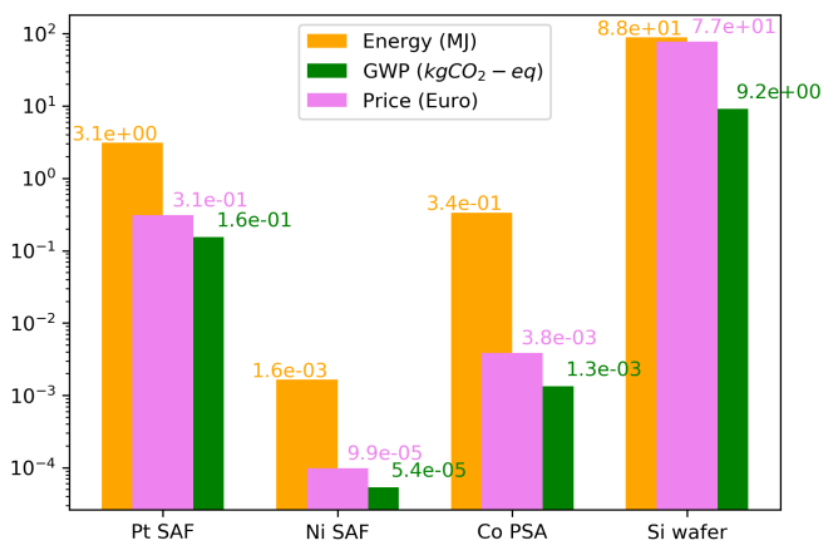

Figure 11. Energy per $300 \mathrm{~mm}$ wafer use, GWP and price in log scale required to obtain the amount of Pt comprised in a conventional SAF, of Co in the PSA based substitution, of $\mathrm{Ni}$ in the case of $(\mathrm{Co} / \mathrm{Ni})$ based $\mathrm{SAF}$ alternative and for the production of a $300 \mathrm{~mm}$ bare Si wafer. The sources for its calculation are given in Supplementary material.

This comparison is made based on the amount of material deposited on a $300 \mathrm{~mm}$ wafer. For the case of PSA, cobalt was used as ferromagnetic material, but other options could be suitable such as $\mathrm{NiFe}$ or $\mathrm{FeCoB}$, which are less critical materials than Co.

The PSA approach increases the mass of material used but the final amount of energy and global warming potential required are strongly decreased, respectively by $89 \%$ and $99 \%$ with respect to the conventional approach based on a synthetic antiferromagnet comprising $(\mathrm{Pt} / \mathrm{Co})$ multilayers. The Pt-free alternative, based on Co only PSA allows for a hundred times smaller carbon footprint. This is evident from the difference in global warming potential between the two materials [36].

In the case of $(\mathrm{Co} / \mathrm{Pt})$ substitution by a $(\mathrm{Co} / \mathrm{Ni})$ based $\mathrm{SAF}$, it can be observed in Figure 11 that even stronger reductions can be achieved, where GWP is reduced up to a factor of $10^{4}$.

However, comparing the global requirements for obtaining the $\mathrm{Pt}$ amount used in the SAF, with those required to produce the silicon wafer itself, the benefits associated with the replacement of $\mathrm{Pt}$ look negligible, independently of the substitution approach. For example, the PSA substitution allows for $2.8 \mathrm{MJ}$ savings per $300 \mathrm{~mm}$ wafer, which representing an $89 \%$ reduction compared to the $\mathrm{Pt} \mathrm{SAF}$ alternative. However, the energy requirements for the $\mathrm{Si}$ wafer fabrication itself amounts to hundreds of MJ, according to recent reported data [32, 37-39]. The same trend is observed for the price and carbon footprint, where the requirements for the $\mathrm{Si}$ wafer are respectively two and one order of magnitude larger.

In Figure 12, the energy, price and GWP required for $\mathrm{Pt}$ production depending on the thin film thickness deposited is displayed and compared to that of the bare $\mathrm{Si}$ wafer, 
represented by the reference black line. It can be seen that for the case of $72.5 \%$ losses during Pt sputtering deposition, the energy equivalent to produce the Si wafer would equal that to produce the Pt required for STT-MRAM fabrication only if the Pt thickness would exceed 50nm, which is more than an order of magnitude larger than what it is used in the current SAF implementation. For GWP and price, it moves to even higher thicknesses. Only in the case of $99 \%$ losses (dotted lines) during deposition, the requirements for Pt would be on the same order than those for the $\mathrm{Si}$ substrate, i.e. a $\mathrm{Pt}$ thickness of $2.25 \mathrm{~nm}$. However, such high losses are not occurring in thin films deposition tools. As mentioned previously, the deposition losses depend on the used tool. In industrial production, equipment suppliers strive to minimize these losses. As can be seen in Figure 12, further reducing the losses during deposition would further decrease the energy, price and GWP requirements associated with Pt use, therefore reducing the benefits of $\mathrm{Pt}$ substitution by using a $\mathrm{Co}$ or $\mathrm{Ni}$ PSA alternative to current Pt SAF in the MRAM reference layer.

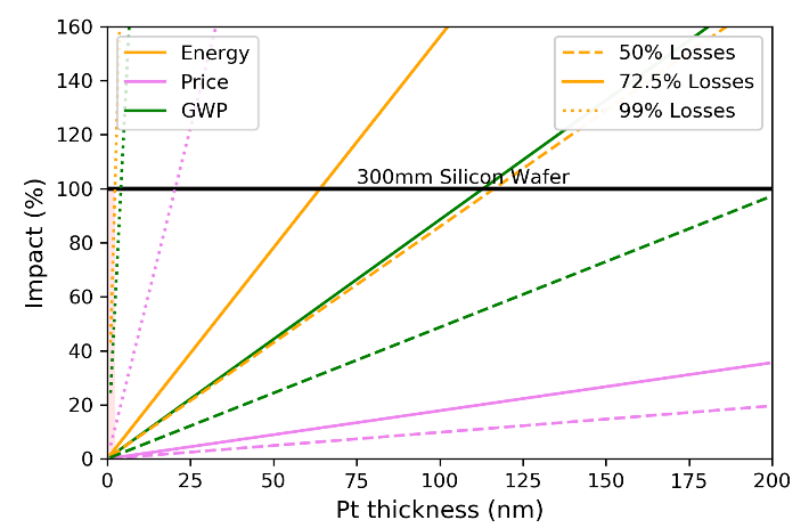

Figure 12. Pt layer thickness on a $300 \mathrm{~mm}$ wafer that would lead to similar figures that for the fabrication of a $300 \mathrm{~mm}$ silicon bare wafer used as a substrate of this technology (different sputtering losses assumed).

Considering the large energy and environmental impacts of the silicon wafer fabrication, it is important to clarify the contribution of each fabrication step in the process, as measured per $\mathrm{kg}$ of $\mathrm{Si}$. This is detailed in Table 1:
Table 1. Energy requirements and yield during the silicon wafer fabrication. The electricity requirements for Si wafer fabrication have been converted to energy for direct comparison with the other raw materials requirements. (3.6 MJ/kWh). Losses related to power plants efficiency have been neglected.

\begin{tabular}{|l|c|c|c|c|}
\hline \multirow{2}{*}{ Fabrication step } & \multicolumn{2}{|c|}{$\begin{array}{c}\text { Electrical energy } \\
\text { (MJ/kg Si output) }\end{array}$} & \multicolumn{2}{c|}{ Si yield (\%) } \\
\cline { 2 - 5 } & $\begin{array}{c}\text { Williams } \\
\text { (2002) } \\
\text { [32] }\end{array}$ & $\begin{array}{c}\text { Takiguchi } \\
\text { (2011) } \\
\text { [38] }\end{array}$ & $\begin{array}{c}\text { Williams } \\
\text { (2002) } \\
\text { [32] }\end{array}$ & $\begin{array}{c}\text { Takiguchi } \\
\text { (2011) } \\
\text { [38] }\end{array}$ \\
\hline $\begin{array}{l}\text { Refining silica to mg- } \\
\text { Si }\end{array}$ & 46.8 & 39.6 & $90 \%$ & $79 \%$ \\
\hline $\begin{array}{l}\text { mg-Si to } \\
\text { trichlorosilane }\end{array}$ & 180 & & $90 \%$ & \\
\hline $\begin{array}{l}\text { Trichlorosilane to } \\
\text { polysilicon }\end{array}$ & 900 & 539.64 & $42 \%$ & $76 \%$ \\
\cline { 1 - 2 } PC-Si to sc-Si ingot & 900 & 111.6 & $50 \%$ & $100 \%$ \\
\hline Sc-Si ingot to Si wafer & 864 & 153 & $56 \%$ & $37 \%$ \\
\hline $\begin{array}{l}\text { Process chain from } \\
\text { silica to wafers }\end{array}$ & 7657.2 & - & $9.5 \%$ & - \\
\hline
\end{tabular}

It can be seen that even adding only the energy used up to the polysilicon step, the requirements correspond to $143 \mathrm{MJ}$ (Williams) and 73.5 MJ (Takiguchi) for a wafer mass of 127 grams, which is well above the calculated 3.1 MJ required for $\mathrm{Pt}$ in the SAF reference layer. Even higher requirements are reported by Ashby [39], 6017MJ per $\mathrm{m}^{2}$ for monocrystalline $\mathrm{Si}$ wafers as microelectronics substrates, leading to $425 \mathrm{MJ}$ for a $300 \mathrm{~mm}$ wafer.

A previous life cycle impact assessment of solar cell fabrication led to a similar conclusion. The authors indeed concluded that the upstream process of silicon wafer fabrication causes higher environmental impact than the solar cell fabrication itself [40]. In that study, it was claimed that an improvement in the wafer production process would be much more beneficial for solar cell fabrication. Improvements in the microelectronics technological process steps have a much higher degree of complexity to be implemented, compared to upstream process improvements. As a matter of fact, our present study related to the impact of Pt substitution in MRAM yields a similar conclusion. The fabrication of the silicon wafers has a stronger energetic and environmental impact than does the use of energy intensive materials as PGMs in the device fabrication process. The root cause for it is the significant mass difference between the $127 \mathrm{~g}$ silicon wafer and 3.4 milligram of $\mathrm{Pt}$ required for the device fabrication.

Boyd [37] already evaluated the GWP associated with the silicon wafer fabrication compared to other phases of the CMOS devices life cycle. The GWP given for a $300 \mathrm{~mm}$ silicon wafer fabrication is of the same order as the GWP for chemicals required during the CMOS fabrication process. However, the main GWP contribution in the device life cycle remains in most cases the actual usage stage. 


\subsection{Supply disruption, is it going to occur?}

Even if the economic and environmental impact of Pt usage remains low in perpendicular STT-MRAM, its potentially high supply risk remains a reason for awareness and substitution strategies are still attractive in this regard.

The high prices of certain resources can lead to technological innovation through the research of alternatives. As an example, higher gasoline prices in Europe compared to the US, might explain a more developed public transport system and a lower per capita consumption. However, as mentioned by Buijs and Sievers, in the case of technology industries, mineral resources availability is a higher concern than price as the cost of these raw materials are often a small share of the final price [41].

Already in 1979, during the Nixon administration, the US government was fearing a possible supply disruption of platinum: "There is a possibility of disruption of supplies from Rhodesia as a result of internal disorders, and a more remote one in the case of South Africa. This would seriously affect US, European, and Japanese imports of two critical materials - platinum and chromium. There is also a possibility of sudden changes in export availability of these two materials from our other major supplier, the Soviet Union, because of our limited advance knowledge of political and economic factors determining its export plans." [42]

Studies regarding possible future material bottlenecks do not predict a future Pt shortage [43,44]. However, Grandell et al. predicted a reinforcement of Pt mining which is undesirable due to its high environmental impact [43]. Zientec et al. declared that the availability and accessibility of PGMs could be disrupted by economic, environmental, political and social events [45]. Previous disruptions have been observed for Pd in 1999 and 2000 due to the blockade of exports from Russia, or for the disruption in Pt supply in 1986, 2011 and 2012 due to miner strikes in South Africa [46].

$\mathrm{Ku}$. A (2018) concluded that the use of PGMs for gate layers in some FeRAM and MRAM device structures can be problematic in terms of future supply due to the small annual production of Pt and Ir [1].

In terms of production, $765 \mathrm{~kg}$ of Pt were necessary in Western Europe for electronic devices such as hard disk drives (HDDs) in 2019 [47]. This could be covered by the European platinum production of about 1 ton. However, a total $~ 56$ tons of Pt were required in the EU for various applications, 41 tons of which are required for automotive needs, far above its own production.

If one focuses on perpendicular STT-MRAM, to meet the world wafer production of December 2019 dedicated to memory corresponding to 7.47 million wafers [48] and assuming that all wafers would contain the SAF comprising $\mathrm{Co} / \mathrm{Pt}$ multilayers, which is an unrealistic upper boundary, 436 $\mathrm{kg}$ of Pt would be required for this annual production. This is the same order as for EU Pt requirements for electrical applications and would represent about $10 \%$ of global $\mathrm{Pt}$ requirements for electrical applications in 2019 ( $\sim .1$ tons) [47], highlighting a higher demand from other technologies such as HDDs.

What this tells us is that even if supply risk is high for PGM group of metals, and the production is very concentrated as shown in Figure 7a, the supply requirements of Pt for STTMRAM are minor when compared to the total production.

It is important to note that the about $5 \mathrm{gr}$ contained in every catalytic converter of diesel cars are much easier to recycle than the Pt present in MRAM devices. Nevertheless, the Pt lost during deposition because being deposited aside of the wafers in the sputtering unit can be at least partially recovered. However, the Pt which is etched away of the wafer during the memory cell nano-patterning process will always be difficult to recover. A fully closed loop of Pt seems difficult to achieve. Therefore, trying to substitute Pt by less critical materials seems to be the best option.

\subsection{Substitution of Co/Pt by using PSA}

Perpendicular Shape Anisotropy (PSA) has been recently implemented in the storage layer of STT-MRAM to enhance its downsize scalabilty [49-52]. In these previous studies, the storage layer thickness was increased in order to enhance the thermal stability down to sub-10nm diameters where conventional STT-MRAM based on interfacial anisotropy is no longer stable. The thermal stability of a magnetic layer in macrospin approximation when its diameter is typically below $20 \mathrm{~nm}$ is given by [49]:

$\Delta=\frac{E_{b}}{k_{B} T}=\left(\frac{\mu_{0} M_{s}^{2}}{2} t\left(N_{x x}-N_{z z}\right)+K_{u} t+K_{s}\right) \frac{\pi D^{2}}{4 k_{B} T}$

where $\mathrm{k}_{\mathrm{B}}$ and $\mu_{0}$ are respectively the Boltzmann constant and the vacuum magnetic permeability and $\mathrm{T}$ the temperature. $\mathrm{D}$ and $t$ denote the cylindrical storage layer diameter and thickness respectively. The other parameters are related to the magnetic properties of the used material: $\mathrm{M}_{\mathrm{S}}$ is the saturation magnetization, $\mathrm{K}_{\mathrm{s}}$ is the interfacial anisotropy at the interface between the tunnel barrier and the magnetic storage layer (most often a $\mathrm{MgO} / \mathrm{FeCoB}$ interface) and $\mathrm{K}_{\mathrm{u}}$ stands for a possible uniaxial magnetocristalline or magnetoelastic anisotropy. $\mathrm{N}_{\mathrm{xx}}$ and $\mathrm{N}_{\mathrm{zz}}$ are respectively the in-plane and outof-plane demagnetizing factors.

In conventional STT-MRAM, the interfacial anisotropy is used to pull the magnetization out-of-plane with a thermal 
stability $\Delta$, targeting $60-100 \mathrm{k}_{\mathrm{B}} \mathrm{T}$ at room temperature to fulfill industrial memory retention requirements. However, as seen in equation (3), the overall anisotropy directly depends on the cell area $\left(\frac{\pi D^{2}}{4}\right)$, meaning that the thermal stability decreases with the diameter so that below a certain diameter of the order of $25 \mathrm{~nm}$, the retention requirements can no longer be satisfied. In order to scale STT-MRAM below $25 \mathrm{~nm}$, one possibility is to have the magnetostatic shape anisotropy energy of density $\frac{\mu_{0} M_{s}^{2}}{2}\left(N_{x x}-N_{z z}\right)$ contribute to the total out-of-plane anisotropy. By increasing the aspect ratio (t/D) of the storage layer, the shape anisotropy term becomes positive and adds to the interfacial anisotropy term making possible to realize thermally stable memory cells of diameters as small as $4 \mathrm{~nm}$ provided that the storage layer is thick enough. [49,50]

The same strategy can be applied for the reference layer in the context of Pt substitution. The idea is to substitute the $\mathrm{Co} / \mathrm{Pt}$ based SAF by a common ferromagnetic material with high enough aspect ratio so that its anisotropy is larger than that of the storage layer as depicted in Figure 2d. However, the nanofabrication of such small structures remains challenging. Indeed, a strict control over the diameter is required in order to precisely control the aspect ratio defining the magnetic properties of the magnetic layer and fabricate a functional device.

\subsection{Substitution of Co/Pt SAF by Co/Ni SAF}

A simpler approach for the substitution of $\mathrm{Pt}$ is to directly use a less critical material which is nickel. Indeed, it was shown that $\mathrm{Ni}$ is also able to provide perpendicular anisotropy when combined with cobalt in the form of $(\mathrm{Co} / \mathrm{Ni})$ multilayers [5357]. 31.7 million of euros are dedicated to projects in the EU to substitute PGMs in various applications for catalysts [58]. In the present study, it is shown that the substitution of $\mathrm{Co} / \mathrm{Pt}$ multilayers for MRAM devices is possible by using $\mathrm{Co} / \mathrm{Ni}$ multilayers.

A key point for achieving strong PMA in $(\mathrm{Co} / \mathrm{Ni})$ multilayers is to induce a good (111) texture of these multilayers. Jan et al. studied the magnetic properties of $\mathrm{Co} / \mathrm{Ni}$ multilayers as a function of the seed layer used [28]. They stated that $\mathrm{NiCr}$, $\mathrm{NiFeCr}$, Hf or a composite seed layer of those materials is preferred to yield the desired texture. Liu et al. studied the behavior of the multilayers grown on $\mathrm{NiCr}, \mathrm{Pt}$, Ta or $\mathrm{Ru}$ seed layers after annealing at $400^{\circ} \mathrm{C}$ [56]. They classified the multilayers grown on $\mathrm{NiCr}$ as exhibiting high PMA, those on $\mathrm{Pt}$ or Ta as medium PMA and finally those on Ru as having a low PMA. As seen in those studies, the seed layer has a fundamental impact on the multilayer PMA properties.

Bloemen et al. already tried growing $(\mathrm{Co} / \mathrm{Ni})$ multilayers on $\mathrm{Cu}$ but using thick 50nm seed layers [53]. Chen et al. used a buffer structure of $1.5 \mathrm{~nm} \mathrm{Cr} / 100 \mathrm{~nm} \mathrm{Cu} / 20 \mathrm{~nm} \mathrm{Pt} / 10 \mathrm{~nm} \mathrm{Cu}$ [57]. In these two cases, relatively thick $\mathrm{Cu}$ seed layers were used.

Zhang et al. reported a seed of $1 \mathrm{~nm} \mathrm{Ta} / 3 \mathrm{~nm} \mathrm{Ti} / 3 \mathrm{~nm} \mathrm{Cu}$ to be effective in enhancing PMA and coercive field of $(\mathrm{Co} / \mathrm{Ni})$ multilayer stacks [55]. They further investigated several methods to improve PMA by plasma treatment or using an oxygen surfactant layer. Wang et al. also studied $\mathrm{Co} / \mathrm{Ni}$ multilayers grown on $3 \mathrm{~nm} \mathrm{Ta} / 2.8 \mathrm{~nm} \mathrm{Cu}$ [54].

In all these previous cases, the studies were limited to the PMA obtained in multilayer structures but not directly in a SAF structure. Arora et al. studied the growth of a SAF structure for spin valves based on $(\mathrm{Co} / \mathrm{Ni})$ multilayers [59]. When growing on a $3 \mathrm{~nm}$ thick $\mathrm{Cu}$ seed, the multilayers achieved coercive field value of about $2 \mathrm{kOe}$.

$\mathrm{NiCr} / \mathrm{Hf}$ was also reported to be a good seed layer for the growth of a SAF made of $\mathrm{Co} / \mathrm{Ni}$ multilayers, resulting in a reference layer with about $1.5 \mathrm{kOe}$ coercivity [26] or even up to more than $5 \mathrm{kOe}$ by using a CoFeBTa spacer layer in an ultrathin p-SAF structure [27]. This work demonstrated that STT-MRAM cells could be fabricated without resorting to Ptbased multilayers.

As explained in the introductory section, the use of $\mathrm{Cu}$ instead of $\mathrm{Hf}$ has the advantage that copper is not a critical material due to its large availability and less centralized production, as seen in Figure 8. Since our goal is to develop a magnetic tunnel junction comprising a SAF structure with reduced use of critical materials, previous buffers such as Hf proposed by Kar et al. [26] or Tomczak et al. [27] were excluded. A similar structure to that of Arora et al. [59] was chosen in which only $\mathrm{Cu}$ was used as buffer layer. By optimizing the $\mathrm{Co} / \mathrm{Ni}$ ratio and using a low roughness $\mathrm{Cu}$ seed layer, switching fields as high as $3.8 \mathrm{kOe}$ could be obtained after $300^{\circ} \mathrm{C}$ annealing, similar to the values of $\mathrm{Co} / \mathrm{Pt}$ based $\mathrm{SAF}$ as shown in the following section. Moreover, after a $400^{\circ} \mathrm{C}$ annealing, by using a composite B getter layer and a slightly thicker $\mathrm{Cu}$ seed of $5 \mathrm{~nm}$, the stability of the SAF could be increased up to $5 \mathrm{kOe}$.

\section{Samples and methods}

The substrates used in these experiments are thermally oxidized silicon wafers. The samples were grown by dcmagnetron sputtering, while the $\mathrm{MgO}$ was prepared by natural oxidation of a thin $\mathrm{Mg}$ layer at 0.03 mbar. Post-deposition annealing was performed in a high-vacuum flash anneal oven for 10 minutes at $300^{\circ} \mathrm{C}$ and $400^{\circ} \mathrm{C}$. Three different samples were grown in order to compare the magnetic properties of $\mathrm{Co} / \mathrm{Pt}$ multilayers-based SAF with those of $\mathrm{Co} / \mathrm{Ni}$ multilayersbased SAF. Sample (1) based on $(\mathrm{Co} / \mathrm{Pt})$ multilayers has the following composition (thickness in $\mathrm{nm}$ ): 
Ta3/Pt25/[Co0.5/Pt0.25] $/$ /Co0.5/Ru0.9/[Co0.5/Pt0.25] $]_{3} /$ $\mathrm{Co} 0.5 / \mathrm{Ta} 0.2 / \mathrm{FeCoB} 1.2 / \mathrm{MgO} 0.75 / \mathrm{Ox}(30 \mathrm{sec}) / \mathrm{MgO} 0.5 / \mathrm{FeCo}$ B1.5/Capping layer

Samples (2 and 3) are based on $(\mathrm{Co} / \mathrm{Ni})$ multilayers and Ptfree and has the following composition (thickness in $\mathrm{nm}$ ):

$2: \mathrm{Ta} 22 / \mathrm{FeCoB} 0.8 / \mathrm{Ta} 3 / \mathrm{Cu} 3 /[\mathrm{Co} 0.2 / \mathrm{Ni} 0.4]_{6} / \mathrm{Co} 0.5 / \mathrm{Ru} 0.9 / \mathrm{Co}$ $0.5 /[\mathrm{Co} 0.2 / \mathrm{Ni} 0.4]_{3} / \mathrm{Ta} 0.2 / \mathrm{FeCoB} 1.2 / \mathrm{MgO} 0.75 / \mathrm{Ox}$

(30sec) $/ \mathrm{MgO} 0.5 / \mathrm{FeCoB} 1.5 /$ Capping layer

$3: \mathrm{Ta} 22 / \mathrm{FeCoB} 0.8 / \mathrm{Ta} 3 / \mathrm{Cu} 5 /[\mathrm{Co} 0.18 / \mathrm{Ni} 0.55]_{6} / \mathrm{Co} 0.5 / \mathrm{Ru} 0.9 /$

Co0.5/[Co0.18/Ni0.55] $/$ Composite Ta getter layer $/ \mathrm{FeCoB} 1.2 / \mathrm{MgO} 0.75 / \mathrm{Ox}(30 \mathrm{sec}) / \mathrm{MgO} 0.5 / \mathrm{FeCoB} 1.0 / \mathrm{Ta} 0.3 / \mathrm{F}$ eCoB0.8/MgO0.75/Ox $(1 \mathrm{sec}) / \mathrm{Mg} 0.5 / \mathrm{FeCoB} 0.4 / \mathrm{Capping}$ layer

\section{Results}

The macroscopic magnetic properties of the samples were studied by vibrating sample magnetometry (VSM). Figure 13a shows hysteresis loops for both sample (1) with a SAF based on $\mathrm{Co} / \mathrm{Pt}$ multilayer in magenta and sample (2) with a SAF based on $\mathrm{Co} / \mathrm{Ni}$ multilayers in green up to $15 \mathrm{kOe}$ fields after $300^{\circ} \mathrm{C}$ annealing process. Sample (2) with SAF based on $\mathrm{Co} / \mathrm{Ni}$ multilayers shows a spin-flop behavior characterized by an abrupt transition at $3.8 \mathrm{kOe}$ at increasing field and a gradual transition back to the antiparallel configuration at $2.5 \mathrm{kOe}$ at decreasing field. In comparison, the switching field of the SAF based on $(\mathrm{Co} / \mathrm{Pt})$ multilayers at increasing field takes place at $4 \mathrm{kOe}$ which is just slightly higher than the $(\mathrm{Co} / \mathrm{Ni})$ based SAF.

Figure 13b shows hysteresis loops for sample (1) and (3) after annealing at $400^{\circ} \mathrm{C}$. In order to achieve higher annealing tolerance, a composite B getter layer was used. Figure 13d shows that the $\mathrm{SAF}$ based on $(\mathrm{Co} / \mathrm{Ni})$ multilayers exhibits an increase of its stability up to $5 \mathrm{kOe}$ demonstrating that BEOL compatibility can be achieved with such multilayers.

Further studies still need to be performed to evaluate the stability of such nickel based SAF in patterned MTJs. Nevertheless, the results shown here are quite encouraging.
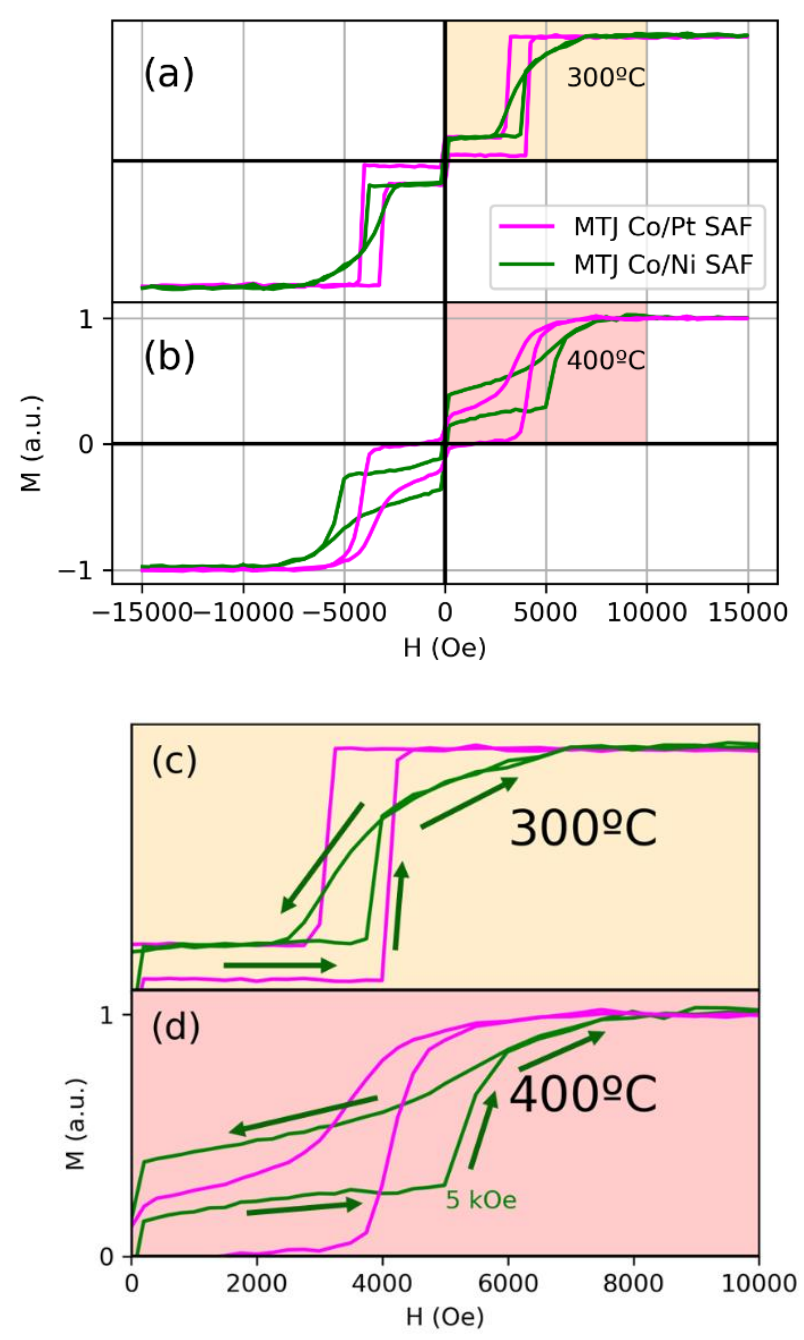

Figure 13. (a) VSM measurements on a conventional SAF based on Co/Pt multilayers (magenta-sample1) versus a SAF comprising $\mathrm{Co} / \mathrm{Ni}$ multilayers (green-sample2) after 300 annealing. (b) VSM measurements on a conventional SAF based on Co/Pt multilayers (magenta-sample1) versus a SAF comprising Co/Ni multilayers (green-sample3) after 400 o annealing (c,d) Zoom of ( $a, b$ respectively) where the ascending and descending branches of the hysteresis loop are indicated by the arrows.

In previous studies of $\mathrm{Co} / \mathrm{Ni}$ based $\mathrm{SAF}$ structures, up to $5 \mathrm{kOe}$ switching fields were reported on $\mathrm{Hf} / \mathrm{NiCr}$ seed layer after $300 \mathrm{C}$ annealing [27] or $2 \mathrm{kOe}$, using $3 \mathrm{~nm} \mathrm{Cu}$ seed [59]. In the present case, high switching fields of $3.8 \mathrm{kOe}$ after $300^{\circ} \mathrm{C}$ and up to $5 \mathrm{kOe}$ after $400^{\circ} \mathrm{C}$ annealing are observed using a thin $\mathrm{Cu}$ seed layer with the particular advantage of the absence of critical materials in the seed layer. Considering that the obtained coercivity of the developed $(\mathrm{Co} / \mathrm{Ni})$ based $\mathrm{SAF}$ is much higher than the typical storage layer coercivity $\sim 2 \mathrm{kOe}$ in STT-MRAM cells, these Co/Ni SAF structures without Pt appear to be a good alternative with a reduced supply risk. 


\section{Other material concerns}

Magnesium is a key material for STT-MRAM as its oxide form provides outstanding TMR properties, not reproduced until the moment by any other type of metal oxide. Despite its abundance in nature, its global production is highly concentrated in China (87\%), which leads it to be identified as a material with "high supply risk" by the European Commission [14].

China already imposed certain measures affecting exports of magnesium, which EU, USA and Mexico already claimed is against the World Trade Organization (WTO) rules [60].

However, due to the truly tiny amounts of magnesium required in p-STT MRAM, the availability of this material should not be a constraint for the development of the technology. In addition, the oxide barrier can be also deposited directly from its oxide form.

Two other important components for STT-MRAM are Ta and $\mathrm{W}$, both being used as boron getters. Boron is absorbed from the interfacial FeCoB layer. The amorphous electrode is used to promote the bcc (001) crystallization of the magnesium oxide tunnel barrier, which is difficult to achieve starting from the fcc crystal structure that maximizes the PMA properties of $\mathrm{Co} / \mathrm{Ni}$ or $\mathrm{Co} / \mathrm{Pt}$ multilayers. This bcc crystallization is indeed responsible for the increased TMR value of $\mathrm{MgO}$ based magnetic tunnel junctions.

The introduction of the EU's new Conflict Minerals Regulation in January 2021 addresses the case of both Ta and $\mathrm{W}$ [3]. The main goal of this regulation is to end the trade and usage of conflict minerals and metals by global smelters and refiners, as well as the abuse of mine workers. Therefore, the objective of this regulation is to force EU companies to import those metals only from responsible sources. Ta is mainly produced by Rwanda (31\%), Democratic Republic of Congo (19\%) and Brazil (14\%) while W primary producers are China $(84 \%)$ and Russia (4\%). Although W has been demonstrated to yield higher annealing tolerance and effective PMA [61], a Ta getter provides acceptable performance.

Initiatives such as the one taken by the EU can lead to a more sustainable supply chain management (SSM), as mentioned by Ageron et al., "suppliers aware of sustainable issues will naturally be more involved in SSM" [62].

\section{Conclusions}

The presence of critical materials in many «clean technologies» put into debate their real benefits. In this report, the case of platinum use in p-STT-MRAM was evaluated. The high embodied energy of platinum is a consequence of the low concentration of the element in the ores, mostly originating from South Africa. Alternatives as recycling are interesting but the recycling efficiency depends a lot on the products to be recycled. For electronic devices, the efficiency is particularly low, of the order of 5-10\% of recovered material. Besides, material losses take place during the deposition of the material by sputtering resulting in a significant fraction of the material being lost on the sidewalls of the sputtering chamber and during the subsequent etch process. Substitution strategies, such as $\mathrm{Co} / \mathrm{Ni}$ multilayers or perpendicular shape anisotropy (PSA) based STT-MRAM are interesting alternatives for a sustainable transition. They reconcile the benefits of lower energy consumption through the non-volatile character of MRAM technology, while also resolving the dependence on critical metals. An evaluation of the energy requirements, global warming potential and price for the use of Pt in perpendicular STT-MRAM has been reported in this paper. The impact of its substitution by using one or the other of the proposed approaches would lead to important reductions in all three investigated figures. However, when comparing those reductions with the requirements for the bare silicon wafer substrate itself, we conclude that the environmental and economic impact of Pt substitution in the SAF of STT-MRAM is not so significant. The energy to fabricate a $300 \mathrm{~mm}$ Si wafer is at least 23 times larger than for the extraction of the Pt used in a reference layer SAF structure. The GWP is 100 times larger for the $\mathrm{Si}$ wafer production. Furthermore, the cost of a Si wafer is a few tens of euros while the estimated cost of Pt needed to prepare the SAF of a STTMRAM on $300 \mathrm{~mm}$ wafers is of about 30 cents. We note that this conclusion was reached based on environmental considerations related to energy and GWP while other aspects not discussed here (political risks, ethics...) should also be taken into account.

The previous points lead us to conclude that the importance of the Pt substitution is related to a potentially high supply risk that PGMs have considering that their production is concentrated in the hands of a few mining companies that are responsible for $80 \%$ of the world Pt production.

As mentioned above, ethics, social and political issues have not been discussed in this report despite their importance. Indeed, as we start observing, consumers who are nowadays better informed, are more and more seeking at using products that are produced in a responsible way. This responsibility concerns climate change, environmental impact, resources, pollution, workers and human rights, secure supply chain management, irresponsible marketing, anti-social finance, and political activities. Broadening our vision of substitution impact, it is valuable to integrate all these aspects in a systemic perspective. The substitution of $\mathrm{Co} / \mathrm{Pt}$ by $\mathrm{Co} / \mathrm{Ni}$ based $\mathrm{SAF}$ is a credible candidate to reduce the impact of Pt use and would 
contribute to the general effort to propose a more sustainable future to the world.

\section{Conflicts of interest}

There are no conflicts to declare.

\section{Acknowledgements}

This work is supported by the French National Research Agency in the framework of the "Investissements d'avenir" program (ANR-15-IDEX-02) and forms part of the NEED for IoT project by the University of Grenoble Alpes (UGA).

\section{References}

1. Ku, A. Y., 2018. Anticipating critical materials implications from the Internet of Things (IOT): Potential stress on future supply chains from emerging data storage technologies. Sustainable Materials and Technologies, 15, 27-32. doi:10.1016/j.susmat.2017.10.001

2. European Commission, 2020 Critical materials for strategic technologies and sectors in the EU - a foresight study, doi: $10.2873 / 58081$

3. EU's new Conflict Minerals Regulation, 2020 (Available: https://ec.europa.eu/trade/policy/in-focus/conflict-mineralsregulation/regulation-explained/).

4. Reinsel, Gantz, Rydning., 2018 'The Digitization of the World From Edge to Core; IDC White Paper - \#US44413318, Sponsored by SEAGATE. (Available: https://www.seagate.com/files/www-content/ourstory/trends/files/idc-seagate-dataage-whitepaper.pdf)

5. Belkhir, L., Elmeligi, A., 2018. Assessing ICT global emissions footprint: Trends to $2040 \&$ recommendations. Journal of Cleaner Production, 177, 448-463. doi:10.1016/j.jclepro.2017.12.239

6. Andrae, A.S.G., Edler, A.T., 2015. On global electricity usage of communication technology: trends to 2030. Challenges 6, 117-157. doi:10.3390/challe6010117

7. Daniele Ielmini and Stefano Ambrogio 2020. Emerging neuromorphic devices. Nanotechnology 31092001. doi:10.1088/1361-6528/ab554b

8. Apalkov, D., Dieny, B., \& Slaughter, J. M. 2016, Magnetoresistive Random Access Memory. Proceedings of the IEEE, 104(10), 1796-1830. doi:10.1109/jproc.2016.2590142
9. Dieny, B., Goldfarb, R. B., \& Lee, K., 2016. Introduction to Magnetic Random-Access Memory. Hoboken, NJ: John Wiley \& Sons., p.101-164. doi:10.1002/9781119079415

10. Pitron, G., 2018. La guerre des métaux rares: La face cachée de la transition énergétique et numérique. Éditions Les Liens qui libèrent.

11. Blengini, Giovanni Andrea et al., 2017 "Methodology for establishing the EU list of critical raw materials - Guidelines."

European Commission. (Available at:
https://op.europa.eu/en/publication-detail//publication/2d43b7e2-66ac-11e7-b2f2-01aa75ed71a1)

12. Frenzel, M. et al., 2017. Raw material 'criticality' - sense or nonsense? J. Phys. D: Appl. Phys. 50 123002. doi: 10.1088/1361-6463/aa5b64

13. Chapman, A., Arendorf, J., Castella, T., Tercero Espinoza, L., Klug, S., Wichmann, E., 2013. Study on Critical Raw Materials at EU Level: Final Report. Oakdene Hollins, Fraunhofer ISI, Brussels, Belgium. (Available at: http://ec.europa.eu/DocsRoom/documents/5605/attachments/ $1 /$ translations)

14. European Commission, 2017. Study on the Review of the List of Critical Raw Materials - Critical Raw Materials Factsheets European Commission, doi: 10.2873/398823

15. European Commission, 2017. Study on the Review of the List of Critical Raw Materials - Non critical Raw Materials Factsheets European Commission, doi: 10.2873/49178

16. Hagelüken, B. C., 2012. Recycling the Platinum Group Metals: A European Perspective. Platinum Metals Review, 56(1), 29-35. doi:10.1595/147106712x611733

17. Raymond, T., Clifford, B., 2019. Low supply growth from recycled platinum will not offset lower mine supply in 2020, Platinum Perspectives, World Platinum Investment Council. (Available at: https://platinuminvestment.com/files/422346/WPIC_Platinu m_Perspectives_November_2019.pdf)

18. Hagelüken, C., \& Corti, C. W., 2010. Recycling of gold from electronics: Cost-effective use through 'Design for Recycling'. Gold Bulletin, 43(3), 209-220. doi:10.1007/bf03214988

19. Johnson Matthey PGM Market Report. (Available at: http://www.platinum.matthey.com/documents/market-datatables/platinum/pdf-2004-to-2013.pdf)

20. Johnson Matthey PGM Market Report. 2020 (Available at: http://www.platinum.matthey.com/documents/new- 
item/pgm\%20market\%20reports/pgm-market-report-may2020.pdf)

21. UKERC. 2014. Materials availability for low-carbon technologies: an assessment of the evidence. 2014. (Available at:

http://www.ukerc.ac.uk/asset/34D2BFC5\%2D9C0D\%2D4C 07\%2DBA6CD6D15BDE549A/)

22. Johnson Matthey 2020. Price charts. (Available at: http://www.platinum.matthey.com/prices/price-charts)

23. U.S. Geological Survey, 2019. Mineral commodity summaries 2019: U.S. Geological Survey, 200 p., doi: $10.3133 / 70202434$

24. Behn, Daniel, December 17, 2007. The Potential Problem with Dual Gas Pricing Practices at the WTO. doi: $10.2139 /$ ssrn. 1151553

25. Sinsalo, Pia, and Mari Lundström, 2018. Refining Approaches in the Platinum Group Metal Processing Value Chain-A Review. Metals, vol. 8, no. 4, p. 203. doi:10.3390/met8040203.

26. Kar, G. S., Kim, W., Tahmasebi, T., Swerts, J., Mertens, S., Heylen, N., Min, T., 2014. Co/Ni based p-MTJ stack for sub-20nm high density stand alone and high performance embedded memory application. 2014 IEEE International Electron Devices Meeting. doi:10.1109/iedm.2014.7047080

27. Tomczak, Y., Lin, T., Swerts, J., Couet, S., Mertens, S., Liu, E., . . . Furnemont, A, 2016. Influence of the Reference Layer Composition on the Back-End-of-Line Compatibility of Co/Ni-Based Perpendicular Magnetic Tunnel Junction Stacks. IEEE Transactions on Magnetics, 52(7), 1-4. doi:10.1109/tmag.2016.2515109

28. Jan.G, Kula.W, Tong.Y, Wang.J, 2016. Co/Ni multilayers with improved out-of-plane anisotropy for magnetic device applications. US Patent No. 9,478,733 B2.

29. Yale Center for Environmental Law and Policy - YCELP - Yale University, Center for International Earth Science Information Network - CIESIN - Columbia University, and World Economic Forum - WEF. 2014. 2014 Environmental Performance Index (EPI). Palisades, NY: NASA Socioeconomic Data and Applications Center (SEDAC). doi: 10.7927/H4416V05.

30. Rankin, J., 2012. Energy Use in Metal Production CSIRO, High Temperature Processing Symposium 2012, Swinburne University, Melbourne, Australia, 6-7 February 2012. Faculty of Engineering and Industrial Sciences, Swinburne University of Technology. 7-9. (Available at:
https://publications.csiro.au/publications/\#publication/PIcsiro :EP12183/SQenergy\%20use\%20in\%20metal\%20production \%20rankin/RP1/RS25/RORECENT/STsearch-bykeyword/LISEA/RI1/RT1)

31. Norgate, Terry \& Lovel, R.R., 2006. Sustainable water use in minerals and metal production. Australasian Institute of Mining and Metallurgy Publication Series. 133-141.

32. Williams, E. D., Ayres, R. U., Heller, 2002. The 1.7 Kilogram Microchip: Energy and Material Use in the Production of Semiconductor Devices. M. Environ. Sci. Technol., 36, 5504-5510. doi: 10.1021/es025643o

33. Walter H. ClassArnold J. AronsonSteven D. HurwittMichael L. Hill, 1984. Focusing magnetron sputtering apparatus. US Patent No. 4,472,259

34. Tolcin, A.C. 2008. Indium. In: 2006 Minerals Yearbook. U.S. Geological Survey, U.S. Department of the Interior. (Available at: http://minerals.usgs.gov/minerals/pubs/commodity/indium/m yb1-2006-indiu.pdf).

35. Rossnagel, 2002. Sputtering and sputter deposition, in Handbook of Thin Film Deposition Processes and Techniques, edited by K. Seshan.

36. Nuss. P, Eckelman. M.J, 2014. Life Cycle Assessment of Metals: A Scientific Synthesis. PLoS ONE 9(7): e101298. doi: 10.1371/journal.pone.0101298

37. Boyd,S. B., 2009. Life-cycle Assessment of Semiconductors. UC Berkeley.(Available at: https://escholarship.org/uc/item/8bv2s63d)

38. Takiguchi, H., 2011. Global Flow Analysis of Crystalline Silicon. Crystalline Silicon - Properties and Uses. doi: $10.5772 / 23573$

39. Ashby, M.F., 2012. Materials and the environment: ecoinformed material choice, 2nd edn. Oxford, UK: ButterworthHeinemann. doi: 10.1016/C2010-0-66554-0

40. Schmidt, M., 2012. Life cycle assessment of silicon wafer processing for microelectronic chips and solar cells. The international journal of life cycle assessment, 17, 126-144. doi: 10.1007/s11367-011-0351-1

41. Buijs B. and Sievers H., 2011, 42 p. (briefing paper), Resource security risks in perspective: complexity and nuance. The Hague: Clingendael International Energy Programme. (Available at: https://www.clingendaelenergy.com/inc/upload/files/Resourc e_security_risks.pdf) 
42. Critical Imported Materials: Study of Ad Hoc Group Established by NSSM 197/CIEPSM 33, US Government (Nixon Administration), July 1974. Available at the US Bureau of Public Affairs, Office of the Historian, 'Foreign Relations of the United States, 1969-1976, Volume XXXI, Foreign Economic Policy, 1973-1976'. (Available at: http://history.state.gov/historicaldocuments/frus1969-76v31)

43. Grandell, L., Lehtilä, A., Kivinen, M., Koljonen, T., Kihlman, S., \& Lauri, L. S., 2016. Role of critical metals in the future markets of clean energy technologies. Renewable Energy, 95, 53-62. doi:10.1016/j.renene.2016.03.102

44. Valero, Alicia \& Valero, Antonio \& Calvo, G. \& Ortego, A., 2018. Material bottlenecks in the future development of green technologies. Renewable and Sustainable Energy Reviews. 93. doi:10.1016/j.rser.2018.05.041.

45. Zientek, M.L., Loferski, P.J., Parks, H.L., Schulte, R.F., and Seal, R.R., II, 2017, Platinum-group elements, chap. N of Schulz, K.J., DeYoung, J.H., Jr., Seal, R.R., II, and Bradley, D.C., eds., Critical mineral resources of the United StatesEconomic and environmental geology and prospects for future supply: U.S. Geological Survey Professional Paper 1802, p. N1-N91. doi:10.3133/pp1802N.

46. Mudd, G.M., 2012. Key trends in the resource sustainability of platinum group elements: Ore Geology Reviews, v. 46, p. 106-117. doi: 10.1016/ j.oregeorev.2012.02.005.

47. World Platinum Investment Council, Q1 2020. Last accessed 05/10/2020. (Available at: https://platinuminvestment.com/files/186857/WPIC_Platinu m_Quarterly_Q1_2020.pdf)

48. Global Wafer Capacity 2020-2024. Last accesed: 05/10/2020. (Available at: https://www.icinsights.com/services/global-wafercapacity/pricing-order-forms/)

49. Perrissin, N., Lequeux, S., Strelkov, N., Chavent. A, Vila. L, Buda-Prejbeanu, L. D., Auffret, S., Sousa, R.C., Prejbeanu, I. L. and Dieny, B. 2018. A highly thermally stable sub-20 nm magnetic random-access memory based on perpendicular shape anisotropy. Nanoscal, 10, 12187-12195. doi:10.1039/C8NR01365A

50. Watanabe, K., Jinnai, B., Fukami, S. et al., 2018 Shape anisotropy revisited in single-digit nanometer magnetic tunnel junctions. Nat Commun 9, 663. doi:10.1038/s41467-01803003-7

51. Perrissin, N., Gregoire, G., Lequeux, S., Tillie, L., Strelkov, N., Auffret, S., . . . Prejbeanu, I. L., 2019.
Perpendicular shape anisotropy spin transfer torque magnetic random-access memory: Towards sub-10 nm devices. Journal of Physics D: Applied Physics, 52(23), 234001. doi:10.1088/1361-6463/ab0de4

52. Lequeux, S., Perrissin, N., Grégoire, G., Tillie, L., Chavent, A., Strelkov, N., . . . Dieny, B., 2020. Thermal robustness of magnetic tunnel junctions with perpendicular shape anisotropy. Nanoscale, 12(11), 6378-6384. doi:10.1039/c9nr10366j

53. Bloemen, P. J., Jonge, W. J., Broeder, F. J, 1992. Magnetic anisotropies in $\mathrm{Co} / \mathrm{Ni}(111)$ multilayers. Journal of Applied Physics, 72(10), 4840-4844. doi:10.1063/1.352048.

54. Wang,G., Zhang,Z., Ma,B., Jin, Q. Y. 2013. Magnetic anisotropy and thermal stability study of perpendicular $\mathrm{Co} / \mathrm{Ni}$ multilayers. J. Appl. Phys. 113, 17C111. doi.org/10.1063/1.4799524

55. Zhang, K., Li.M, Zhou.Y, 2014. Multilayer structure with high perpendicular anisotropy for device applications. US Patent No. 8,920,947 B2.

56. Liu, E., Swerts, J., Devolder, T., Couet, S., Mertens, S., Lin, T., Spampinato, V., Franquet.A, Conard.T, SVan Elshocht.S, Furnemont.A, De Boeck.J, and Kar, G., 2017. Seed layer impact on structural and magnetic properties of $[\mathrm{Co} / \mathrm{Ni}]$ multilayers with perpendicular magnetic anisotropy. Journal of Applied Physics, 121(4), 043905. doi:10.1063/1.4974885

57. Chen.W, Beaujour, J.-M.L., de Loubens, G., Kent, A. D., Sun, J.Z., 2008. Spin-torque driven ferromagnetic resonance of Co Ni Synthetic layers in spin valves. Appl. Phys. Lett. 92, 012507. doi: $10.1063 / 1.2827570$

58. Løvik, A.N., Hagelüken, C., Wäger, P., 2018. Improving supply security of critical metals: Current developments and research in the EU. Sustain. Mater. Techn. 2018, 15, 9-18. doi: 10.1016/j.susmat.2018.01.003

59. Arora, M., Lee-Hone, N. R., Mckinnon, T., Coutts, C., Hübner, R., Heinrich, B., Broun, D. M., Girt, E., 2017, Magnetic properties of $\mathrm{Co} / \mathrm{Ni}$ multilayer structures for use in STT-RAM. J. Phys. D: Appl. Phys. 50 (2017) 505003 (11pp). doi:10.1088/1361-6463/aa97fa

60. Gemechu, E. D., Sonnemann, G., Young, S. B. (2015). Geopolitical-related supply risk assessment as a complement to environmental impact assessment: The case of electric vehicles. The International Journal of Life Cycle Assessment, 22(1), 31-39. doi:10.1007/s11367-015-0917-4 
61. Chatterjee, J., Sousa, R. C., Perrissin, N., Auffret, S., Ducruet, C., \& Dieny, B. (2017). Enhanced annealing stability and perpendicular magnetic anisotropy in perpendicular magnetic tunnel junctions using W layer. Applied Physics Letters, 110(20), 202401. doi:10.1063/1.4983159

62. Ageron, B., Gunasekaran, A., \& Spalanzani, A., 2012, Sustainable supply management: An empirical study. International Journal of Production Economics, 140(1), 168182. doi:10.1016/j.ijpe.2011.04.007 